of this syndrome should be excluded by careful necropsy examination. It has been pointed out that the recurrence rate in bilateral renal agenesis is too high to be explained on the basis of multifactorial inheritance unless estimates of the birth frequency are much too low. ${ }^{8}$ Single gene defects could account for some of this excess and Fraser syndrome is one likely candidate.

We are grateful to the late Professor C O Carter for his helpful comments on this case. We would also like to thank Mrs C McIntyre who typed the manuscript.

\section{References}

1 Azevedo ES, Biondi J, Ramalho LM. Cryptophthalmos in two families from Bahia, Brazil. J Med Genet 1973;10:389-92.
2 Smith DW. Recognizable patterns of human malformation. 3rd ed. Philadelphia: Saunders, 1982:179.

${ }^{3}$ François J. Syndrome malformatif avec cryptophthalmie. Acta Genet Med Gemellol (Roma) 1969;18:18-50.

${ }^{4}$ Fraser CR. Our genetic 'load'. A review of some aspects of genetic variation. Ann Hum Genet 1962;25:387-415.

5 Burn J, Marwood RP. Fraser syndrome presenting as bilateral renal agenesis in three sibs. $J$ Med Genet 1982;19:360-1.

${ }^{6}$ McKusick VA. Mendelian inheritance in man. 6th ed. Baltimore, London: Johns Hopkins University Press, 1983.

7 Yates JRW, Mortimer G, Connor JM, Duke JE. Concordant monozygotic twins with bilateral renal agenesis. $J$ Med Genet 1984;21:66-7.

${ }^{8}$ Carter CO, Evans K, Pescia G. A family study of renal agenesis. J Med Genet 1979;16:176-88.

Correspondence and requests for reprints to $\mathrm{Dr} G$ Mortimer, Department of Pathology, Royal Maternity Hospital, Glasgow G4 0NA.

\title{
Familial opposable triphalangeal thumbs associated with duplication of the big toes
}

\author{
PAUL MERLOB, MICHAEL GRUNEBAUM, AND SALOMON H REISNER
}

Departments of Neonatology and Pediatric Radiology, Beilinson Medical Center, Petah Tiqva, and the Sackler School of Medicine, Tel Aviv University, Tel Aviv, Israel.

SUMMARY A rare association of triphalangeal thumbs and duplication of the big toes is described. The family pedigree confirms autosomal dominant inheritance with marked penetrance. A systematic approach to the diagnosis of this anomaly is presented. The distinction between the two types of triphalangeal thumb, true (opposable) and fingerlike (non-opposable), is emphasised.

A triphalangeal thumb is defined as a thumb with three phalanges in a row. This is a very rare congenital malformation. Wood ${ }^{1}$ reviewed published reports and found 362 patients with 630 triphalangeal thumbs. About two-thirds of these cases had a family history.' However, the familial occurrence of opposable triphalangeal thumbs with duplication of the big toes has rarely been reported. ${ }^{2-5}$ We wish to report a family with this anomaly and to suggest a systematic approach to the infant with triphalangeal thumbs.

\section{Case report}

The family pedigree is shown in fig 1 . The first child

Received for publication 27 January 1984. Accepted for publication 1 June 1984
(V.1) was born in 1981 after a normal pregnancy and delivery to a 30 year old, G2, P1, A1 healthy mother. The parents were unrelated. The pregnancy was normal. There was no history of any medication, alcohol intake, or smoking during pregnancy.

Physical examination revealed a healthy female infant with malformations of both thumbs and big toes. Both thumbs were affected symmetrically. They appeared long with an additional interphalangeal joint and an extra set of skin creases. The thenar region, the first web space, and the nail were

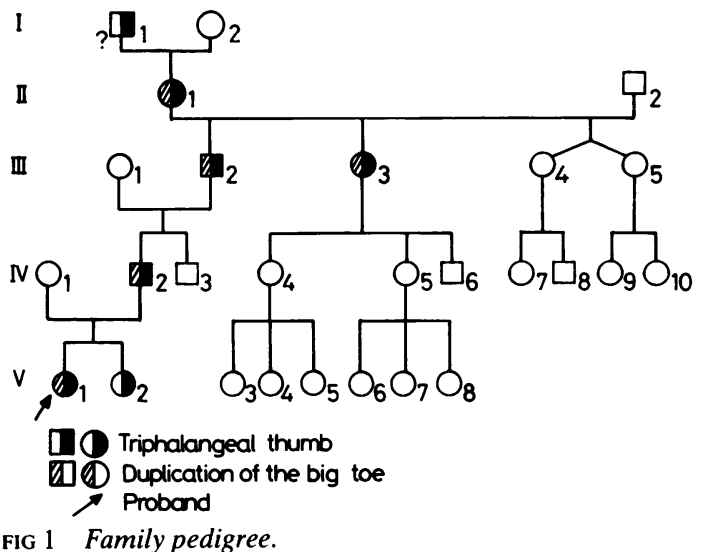


normal. The anatomical position of the thumbs was also normal. The thumbs were opposable although mild restriction in movement at the distal interphalangeal joint was observed. The other fingers were normal.

Both big toes were symmetrically affected, while the other four toes were normal. There was duplication of the big toes with cutaneous syndactyly and two normal nails.

$X$-rays of both hands (fig 2) at birth showed long thumbs with an additional middle phalanx composed of two small ossification centres. The first metacarpal was shorter than usual. The other four fingers and metacarpals had a normal appearance. The bone age of the wrist corresponded to the age of 3 months. There was a slight cupping formation of the metaphyseal region of the distal ulna with a normal provisional zone of calcification. The opposite radius had a normal appearance.

$X$-rays of the feet (fig 3 ) revealed hexadactyly with five metatarsals. The first metatarsal was more distally placed than usual, as compared to the proximal end of the other metatarsal bones, and its distal end was broad. Both big toes were duplicated and were composed of two separate phalangeal bones. The proximal-medial phalanx was shorter and had an oval appearance. All other metatarsal bones and phalanges were normally shaped. Cutaneous syndactyly was present between the duplicated parts of the big toes.

The rest of the skeletal survey, which included $x$-rays of the head, spine, pelvis, and extremities, showed no abnormalities.

The second child (V.2), born in 1983, was a healthy, term girl with normal feet, but with bilateral long thumbs. Her first fingers had an extra set of skin creases, but a normal position and a normal thenar region. The thumbs were opposable.

The father (IV.2) also had triphalangeal thumbs.

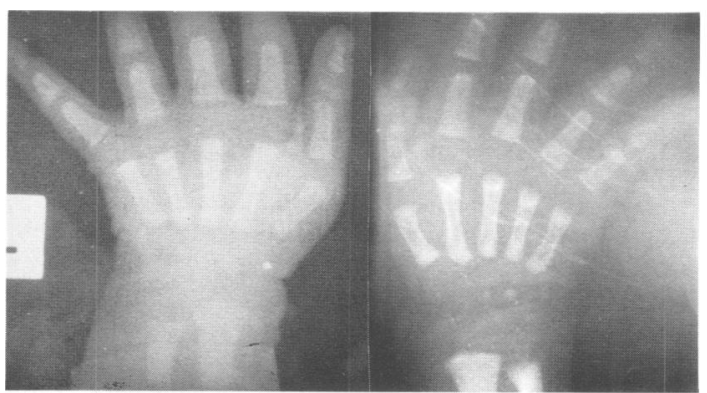

FIG 2 Anteroposterior view of both hands showing bilateral long thumbs with a middle phalanx composed of two small ossification centres. Note slightly shortened first metacarpal and cupping of the distal ulna. Bone age 3 months.

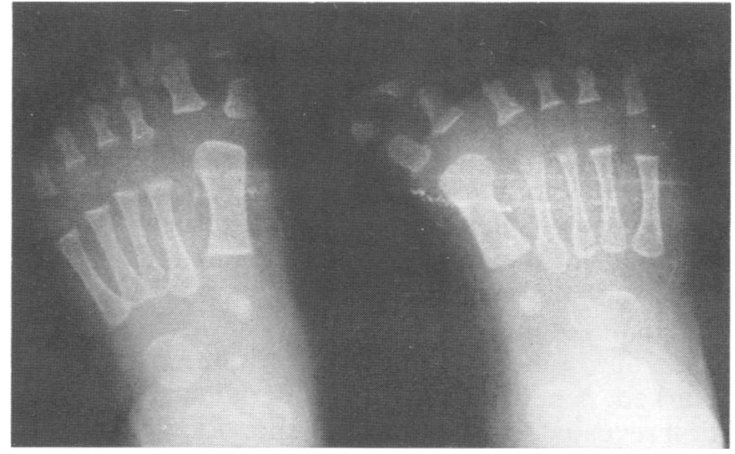

FIG 3 Anteroposterior view of feet showing hexadactyly with five metatarsals. Note broad distal end of first metatarsal. The bone itself is more distally located than usual.

By his description and a photograph, he had duplication of both big toes which were operated on at the age of 4 years. The father is an electronic technician and his anomaly does not interfere with his work.

The grandfather (III.2) and his sister (III.3) have the same symmetrical opposable triphalangeal thumbs and duplication of the big toes. According to the father, his grandmother (II.1) and most probably her father (I.1) had the same anomalies. No other malformations were known in this family. The proband's mother and her family were healthy and without any abnormalities.

\section{Discussion}

Triphalangeal thumb is a rare skeletal malformation. Lapidus et $\mathrm{al}^{6}$ found an incidence of all types of this anomaly in military recruits of 1:25 000 (one case sporadic and two familial). It is often associated with other skeletal anomalies especially of the fingers and toes. ${ }^{1}$ However, the combination of triphalangeal thumbs with duplication of the big toes has rarely been reported. ${ }^{2-5}$ Temtamy and McKusick $^{5}$ briefly described a family with this thumb-hallux association, but the pedigree was not presented. In spite of his opposable triphalangeal thumbs, their patient had a normal first metacarpal and a well developed middle phalanx of the thumbs.

Komai $e t$ al ${ }^{4}$ described a family with triphalangeal thumbs and duplication of the big toes. However, there was great variability in expression between their patients and also in the same patient. An example of this variation is their case IV.18 who had a right finger-like thumb with a well developed middle phalanx and a left true triphalangeal thumb with a short and deformed middle phalanx. 
The occurrence of this anomaly with partial duplication of one big toe was also mentioned by Majewski et al,${ }^{7}$ but their case represer is a different association of triphalangeal thumb $w$ th brachyectrodactyly. Also, the anomaly was the finger-like type, with normal first metacarpals.

The patients described by us have true opposable triphalangeal thumbs with duplication of the big toes in a familial non-syndromic association. Most characteristics of the pedigree under study point strongly to an autosomal dominant mode of inheritance with marked penetrance. The radiographical examination revealed some findings not previously reported. The bone age was advanced, the centres of ossification of the carpal region were already present at birth, and the shape of the middle extra phalanx of the thumbs at birth was that of two small ossification centres.

In order to ensure a systematic approach to the child with triphalangeal thumbs, three questions must be answered. (1) Is it an opposable (true triphalangeal) or non-opposable thumb (fingerlike)? (2) Is it isolated, complicated, or syndromic? (3) Is it sporadic or familial?

(1) The distinction between the two types of triphalangeal thumb is based on the criteria presented in table 1 . The radiological picture plays an important role in this differentiation. The shape of the first metacarpal and the location of its epiphyseal plate, ${ }^{8-10}$ as well as the shape of the middle phalanx of the thumb, ${ }^{110}$ are useful criteria. This differentiation has a very practical significance. The non-opposable, finger-like thumb (five fingered hand) is a difficult functional problem ${ }^{10}$ which must be corrected by surgery (pollicisation).

(2) A triphalangeal thumb without other anomalies defines the isolated defect. In contrast, the syndromic anomaly occurs with other primary defects of morphogenesis. Table 2 summarises various syndromes with triphalangeal thumb known at present. On reviewing these syndromes we observed that many descriptions are incomplete and the type of thumb anomaly is not precisely defined. In the

TABLE 1 Criteria (clinicoradiological) for differentiation between the two types of triphalangeal thumbs.

\begin{tabular}{lll}
\hline Criteria & True anomaly & Finger-like anomaly \\
\hline $\begin{array}{l}\text { Long thumb } \\
\text { Position }\end{array}$ & $\begin{array}{l} \pm \text { to }+ \\
\text { Usually normal }\end{array}$ & $\begin{array}{l}++ \\
\text { In the same plane as the other } \\
\text { digits }\end{array}$ \\
$\begin{array}{l}\text { Thenar muscle } \\
\text { Function }\end{array}$ & $\begin{array}{l}\text { Normal } \\
\text { Opposable, } \\
\text { almost normal rotation }\end{array}$ & $\begin{array}{l}\text { Non-opposable, restriction of } \\
\text { movements } \\
\text { Fong, } \\
\text { distal epiphyseal centre }\end{array}$ \\
Extra phalanx & $\begin{array}{l}\text { Short, epiphysis at } \\
\text { proximal end }\end{array}$ & $\begin{array}{l}\text { Usually full phalanx } \\
\text { Usulta phalanx }\end{array}$ \\
\hline
\end{tabular}

TABLE 2 Syndromes with triphalangeal thumb.

\begin{tabular}{|c|c|}
\hline Haematological & $\begin{array}{l}\text { Aase syndrome } \\
\text { Blackfan-Diamond aplastic anaemia } \\
\text { Fanconi anaemia }\end{array}$ \\
\hline Chromosomal & $\begin{array}{l}\text { Trisomy } 13-15 \\
\text { Cat-eye syndrome }\end{array}$ \\
\hline Drugs & $\begin{array}{l}\text { Thalidomide embryopathy } \\
\text { Fetal hydantoin syndrome }\end{array}$ \\
\hline Visceral & $\begin{array}{l}\text { Holt-Oran syndrome } \\
\text { Townes-Brocks syndrome } \\
\text { Congenital deafness and onychodystrophy } \\
\text { (DOOR syndrome) } \\
\text { Lacrimo-auricular-dento-digital syndrome } \\
\text { IVIC syndrome }\end{array}$ \\
\hline Skeletal & $\begin{array}{l}\text { Eaton-McKusick syndrome } \\
\text { Triphalangeal thumb and brachyectrodactyly }\end{array}$ \\
\hline
\end{tabular}

reports with a good description it was of a nonopposable, finger-like type and not a true, oppos- 은 able triphalangeal thumb as in our patients.

We defined a complicated triphalangeal thumb as $T_{0}$ a thumb with three phalanges in a row associated with other skeletal anomalies (especially of the ฏ) fingers or toes or both) or extraskeletal anomalies, not included in a defined syndrome. It is most often $\vec{\varphi}$ associated with polydactyly of the thumb and big of toe. ${ }^{1}$ This associated polydactyly represents a major surgical problem ${ }^{1}{ }^{10}$ and thus complicates the basic anomaly.

(3) The sporadic occurrence of triphalangeal thumb is relatively uncommon. Usually, it appears $\frac{\gtrless}{\mathbb{Q}}$ to be inherited as a simple autosomal dominant trait with marked penetrance. ${ }^{1}$ Two-thirds of the cases had a family history. ${ }^{1}$

\section{References}

1 Wood VE. Treatment of the triphalangeal thumb. Clin Orthop 1976;120:188-200.

2 Manoiloff EO. A rare case of hereditary hexadactylism. Am J Phys Anthropol 1931;15:503-8.

${ }^{3}$ Hefner RA. Hereditary polydactyly associated with extra phalanges in the thumbs. J Hered 1940;31:25-7.

${ }^{4}$ Komai T, Ozaki Y, Inokuma W. A Japanese kindred of hyperphalangism of thumbs and duplication of thumbs and big toes. Folia Hered Pathol 1953;2:307-12.

5 Temtamy SA, McKusick VA. Synopsis of hand malformations with particular emphasis on genetic factors. Birth Defects 을 1969;5:170.

6 Lapidus PW, Guidoth FP, Coletti CJ. Triphalangeal thumb. 尺 Surg Gynecol Obstet 1943;77:178-86.

${ }^{7}$ Majewski F, Kemperdick M, Goecke T. Triphalangeal thumbsectrodactyly in a sporadic case. Clin Genet 1981;20:310-4.

${ }^{8}$ Lamb DW, Wynne-Davies R, Whitmore JM. Five-fingered hand associated with partial or complete tibial absence and pre-axial polydactyly. J Bone Joint Surg [Br] 1983;65:60-3.

9 Swanson AB, Brown KS. Hereditary triphalangeal thumb. $J$ Hered 1962;53:259-65.

10 Miura T. Triphalangeal thumb. Plast Reconstr Surg 1976;58: 587-94.

Correspondence and requests for reprints to Dr Paul Merlob, Department of Neonatology, Beilinson Medical Center, Petah Tiqua, 49100 Israel. 